\title{
A PRIMEIRA NORMA TÉCNICA PARA CIDADES SUSTENTÁVEIS: UMA REFLEXÃO SOBRE A PROBLEMÁTICA URBANA
}

\author{
Fernando Figueiredo Prestes ${ }^{1}$ \\ Valmir César Pozzetti ${ }^{2}$
}

\begin{abstract}
RESUMO: O objetivo desta pesquisa foi estudar a NBR 37.120/17, a primeira norma técnica para cidades sustentáveis e verificar se há como medir a problemática urbana, no tocante a prestação dos serviços de saneamento ambiental, abastecimento de água, esgotamento sanitário e manejo de resíduos sólidos. A conclusão a que se chegou é de que a norma técnica é um mecanismo eficaz para se mapear o espaço urbano e identificar a prestação dos serviços públicos. A metodologia utilizada na pesquisa foi o método dedutivo e, quanto aos meios a pesquisa foi bibliográfica e quantos aos fins, qualitativa.
\end{abstract}

Palavras-chave: Cidades Sustentáveis; Indicadores Socioambientais; NBR ISO 37.120/17; Norma Técnica; Serviços Públicos.

\section{THE FIRST TECHNICAL STANDARD FOR SUSTAINABLE: CITIES A REFLECTION ON URBAN PROBLEM}

\begin{abstract}
The objective of this research was to study NBR 37.120/17, the first technical standard for sustainable cities and to verify if there is a way to measure urban problems, in relation to the provision of services of environmental sanitation, water supply, sewage and solid waste management. The conclusion reached is that the technical standard is an effective mechanism for mapping the urban space and identifying the provision of public services. The methodology used in the research was the deductive method and, in terms of the means, the research was bibliographical and as to the purposes, qualitative.
\end{abstract}

Keywords: Sustainable Cities. Socio-environmental Indicators. NBR ISO 37,120 / 17. Technical norm. Public services.

\footnotetext{
${ }^{1}$ Defensor Público do Estado do Amazonas, Mestrando em Direito Ambiental - Universidade do Estado do Amazonas - Manaus / AM - uea.edu.br. E-mail: fernandofprestes@ hotmail.com.

2 Doutor em Biodireito/Direito Ambiental pela Université de Limoges/França (título reconhecido pela Univ. Federal de Pernambuco). Mestre em Direito do Urbanismo e do Meio Ambiente, pela Université de Limoges, França (título reconhecido pela Universidade Luterana do Brasil). Bacharel em Direito pelo Centro Integrado de Ensino Superior da Amazônia/AM, Bacharel em Ciências Contábeis pela Faculdade São Luis/SP. É Conselheiro Estadual da OAB/AM no triênio 2016/2018. É Acadêmico Imortal da Academia de Ciências Contábeis do Amazonas.. E-mail: v_pozzetti@hotmail.com
} 


\section{INTRODUÇÃO}

O crescimento das cidades com a migração do homem do campo trouxe diversas mazelas para o ambiente urbano, dentre eles: habitações insuficientes, transportes públicos urbanos ineficazes, esgotamento sanitário inexistente, escassez de água potável canalizada, instalação irregular de lixões, doenças endêmicas e prestações serviços de saúde e educação caóticos.

A relação entre a desigualdade da prestação destes serviços, o mapeamento dos indicadores de sustentabilidade urbano e a possibilidade de utilização da NBR ISO 37.120/17 poderá ser uma das formas de identificação dos problemas e, consequentemente, um instrumento de tomada de decisões para resolução destas adversidades sociais pelos governos locais.

A desigualdade do fornecimento e atendimento do serviço de saneamento ambiental, abastecimento de água, esgotamento sanitário e manejo de resíduos sólidos são outros problemas que ocorrem em várias cidades, mas no presente estudo será feita uma abordagem sobre a realidade da Cidade de Manaus.

A água é um recurso natural limitado, insubstituível, dotado de valor econômico, encontrado nos três estados físicos da matéria, porém, a falta do serviço ou a precariedade do abastecimento de água causam graves problemas para a população urbana, interfere diretamente na qualidade de vida das mesmas, seja para o consumo humano, higiene pessoal, elaboração de alimentos e dessedentação de animais.

A coleta e o tratamento de esgotos domésticos e industriais têm importância na preservação dos recursos naturais e na qualidade de vida. O serviço público de limpeza urbana e manejo de resíduos sólidos, em linhas gerais, compreende a coleta, a remoção e o transporte dos resíduos sólidos domiciliares, a varrição e limpeza de vias e logradouros, a remoção e transporte de resíduos das atividades de limpeza e a transferência dos rejeitos gerados nessas unidades para destino final disposto de forma correta, utilizando aterros sanitários em conformidade com a legislação ambiental.

A ausência de um planejamento estratégico destes serviços pode contribuir para a contaminação dos mananciais hídricos, poluição dos cursos de água, solo, assoreamento dos rios e para a formação de ambientes propícios à proliferação de agentes transmissores de doenças.

Neste sentido, com o intuito de minimizar as mazelas urbanas, a Associação Brasileira de Normas Técnicas (ABNT) editou a NBR ISO 37.120/2017, com o propósito de estabelecer metodologias para um conjunto de indicadores relacionados ao Desenvolvimento Sustentável 
de comunidades urbanas e assim orientar e medir o desempenho de serviços urbanos e a qualidade de vida.

Dessa forma, a problemática que se levanta nessa pesquisa é: de que forma a NBR ISO 37.120/2017 pode auxiliar na efetivação da prestação dos serviços públicos e na identificação dos indicadores socioambientais urbanos?

Sendo assim, o objetivo desta pesquisa é estudar a NBR ISO 37.120/17 e verificar se nesta norma há mecanismos para identificação de indicadores e instrumentos eficazes que auxiliem na tomada de decisões para melhorar a qualidade de vida da população das cidades.

A metodologia a ser utilizada nesta pesquisa é o do método dedutivo, sendo que, quanto aos meios a pesquisa será a bibliográfica, com uso da doutrina e legislação e, quanto aos fins, a pesquisa será a qualitativa.

\section{PROBLEMÁTICA URBANA E A MÁ DISTRIBUIÇÃO DOS SERVIÇOS PÚBLICOS.}

Saneamento ambiental é o conjunto de medidas que objetiva preservar ou modificar as condições do meio ambiente com a finalidade de prevenir doenças e promover a saúde, melhorar a qualidade de vida da população e a produtividade da atividade econômica.

No Brasil o saneamento é um direito assegurado pela Constituição Federal:

Art. 21. Compete à União:

(...) omissis

XX - instituir diretrizes para o desenvolvimento urbano, inclusive habitação, saneamento básico e transportes urbanos;

Art. 23. É competência comum da União, dos Estados, do Distrito Federal e dos Municípios:

(...) omissis

$\mathrm{XI}$ - registrar, acompanhar e fiscalizar as concessões de direitos de pesquisa e exploração de recursos hídricos e minerais em seus territórios;

Art. 200. Ao sistema único de saúde compete, além de outras atribuições, nos termos da lei:

(...) omissis

V - incrementar, em sua área de atuação, o desenvolvimento científico e tecnológico e a inovação;

Art. 225. Todos têm direito ao meio ambiente ecologicamente equilibrado, bem de uso comum do povo e essencial à sadia qualidade de vida, impondo-se ao Poder Público e à coletividade o dever de defendê-lo e preservá-lo para as presentes e futuras gerações. (g.n.)

Em linhas gerais, coube a Lei $n^{0} 11.445 / 2007$, estabelecer as diretrizes nacionais para o saneamento básico e para a política de saneamento básico: 
Art. $2^{\circ}$ Para fins do disposto nesta Lei, considera-se:

I - saneamento básico - conjunto de serviços, infraestruturas e instalações operacionais de:

a) abastecimento de água potável, constituído pelas atividades, pela disponibilização, pela manutenção, pela infraestrutura e pelas instalações necessárias ao abastecimento público de água potável, desde a captação até as ligações prediais e os seus instrumentos de medição;

b) esgotamento sanitário, constituído pelas atividades, pela disponibilização e pela manutenção de infraestrutura e das instalações operacionais de coleta, transporte, tratamento e disposição final adequados dos esgotos sanitários, desde as ligações prediais até a sua destinação final para a produção de água de reuso ou o seu lançamento final no meio ambiente;

c) limpeza urbana e manejo de resíduos sólidos, constituídos pelas atividades, pela infraestrutura e pelas instalações operacionais de coleta, transporte, transbordo, tratamento e destino final dos resíduos sólidos domiciliares e dos resíduos de limpeza urbanas; e

d) drenagem e manejo das águas pluviais urbanas, constituídos pelas atividades, pela infraestrutura e pelas instalações operacionais de drenagem de águas pluviais, de transporte, detenção ou retenção para o amortecimento de vazões de cheias, tratamento e disposição final das águas pluviais drenadas, contempladas a limpeza e a fiscalização preventiva das redes; (g.n.)

O saneamento é um fator essencial para um país poder se desenvolver, pois os serviços de água tratada, coleta e tratamento dos esgotos levam à melhoria da qualidade de vida da população, sobremodo na saúde infantil com redução da mortalidade, melhoria na educação, na expansão do turismo, na valorização dos imóveis, na renda do trabalhador, na despoluição dos rios e preservação dos recursos hídricos.

Merecem atenção especial da esfera pública, a igual abrangência, regularidade e distribuição dos serviços de coleta de lixo, coleta de esgoto e abastecimento de água, pois o comando Constitucional da Dignidade da Pessoa Humana tem como raiz o bem-estar de todos sem distinção de classes, sendo o Poder Público um importante vetor estratégico para implantação destas políticas públicas socioambientais.

As cidades são um dos entes federados que compõem a República brasileira, estando prevista na $\mathrm{CF} / 88$, sendo que a política urbana está assim estruturada:

Art. 182. A política de desenvolvimento urbano, executada pelo Poder Público municipal, conforme diretrizes gerais fixadas em lei, tem por objetivo ordenar o pleno desenvolvimento das funções sociais da cidade e garantir o bem-estar de seus habitantes. (g.n.)

Embora as cidades tenham uma política de desenvolvimento, esta, não ocorre na prática. Exemplo disso se deu entre as décadas de 1980 e de 1990 na cidade de Manaus/AM, onde duas experiências desastrosas demostraram a total falta de planejamento estratégico ambiental. 
A primeira foi a instalação de uma lixeira pública a céu aberto nas margens da Rodovia Estadual AM - 070, próximo ao antigo balneário da Ponte da Bolívia, um dos braços do Igarapé Tarumã-açu, que deságua no Rio Negro que, por sua vez, margeia a cidade de Manaus/AM.

Esta instalação foi fator determinante para a degradação da área e do entorno, com a contaminação do lençol freático, dos igarapés e de todos os cursos d'água, com a consequente perda de vários balneários públicos, como a Ponte da Bolívia, do Tarumã e o da Praia da Ponta Negra.

A empresa que administra o Aeroporto de Manaus é a Empresa Brasileira de Infraestrutura Aeroportuária - INFRAERO (2015, p. 1), e esta relatou que:

\begin{abstract}
A localização da lixeira pública de Manaus é um dos fatores da existências de pássaros (urubus) nas rampas imaginárias de pouso e de decolagem em uma dos lados cabeceira da pista do Aeroporto Internacional Eduardo Gomes, com vários registro de incidentes aeronáuticos no local, em total desacordo com o artigo 43, da seção V, do capítulo II, do título III, da Lei $\mathrm{n}^{\circ} 7.565$, de 19 de dezembro de 1986, que estabelece que as propriedades vizinhas dos aeródromos e as instalações de auxílio à navegação aérea estão sujeitas a restrições especiais.
\end{abstract}

A outra experiência ocorrida na cidade de Manaus/AM foi descrita por Botelho (2015, p. 32): "a instalação irregular de uma invasão popular de casebres na área verde do entorno da estação de capitação de água da 'Ponta do Esmael', que lançava esgoto e detritos fecais próximos a única fonte de captação de água da cidade”.

Este fato ocorreu em um período da história da cidade de Manaus/AM, em que o país vivia uma crise sanitária com vários registros de cólera no Brasil. Segundo o Portal Brasil (2018, p. p), "em abril de 1991, a cólera chegou novamente ao Brasil vindo do Peru". Por estes motivos as autoridades sanitárias, da época, recomendaram a remoção imediata desta invasão denominada favela meu bem meu mal, pois a mesma despejava resíduos sanitários não tratados e domésticos diretamente no Rio Negro nas áreas próximas a central de captação de água potável da cidade.

Segundo Ferrajoli (2006, p. 78):

A água tornou-se um bem escasso por dois motivos: pelas agressões ao patrimônio florestal, que provocam todo ano a devastação de milhões de hectares, muitos dos quais viram deserto; pela poluição das nascentes dos rios e dos aquíferos, provocados pelas atividades industriais desreguladas; pelo não tratamento dos esgotos e pela massiva privatização, enfim, dos recursos hídricos que paradoxalmente são reduzidos a bens patrimoniais no mesmo momento em que se exige, pela sua escassez, a sua garantia como bens fundamentais. 
Assim, este autor nos ensina que os erros que a humanidade comete com o uso da água, faz com que este recurso natural, tão fundamental à existência da vida, se torne cada vez mais escassa e poluído.

Desse modo, apresenta-se estes dois exemplos da cidade de Manaus/AM para se ilustrar que a falta de planejamento estratégico na implantação de serviços públicos prejudica a população urbana, com reflexo imediato sobre o meio ambiente, pois segundo preleciona Silva (2004, p. 58):

\begin{abstract}
a proteção ambiental, abrange a preservação da natureza em todos os seus elementos essenciais à vida humana e à manutenção do equilíbrio ecológico, objetivando tutelar a qualidade do meio ambiente em função da qualidade de vida, como forma de um direito fundamental da pessoa humana. Desse modo, incumbe ao Poder Público zelar pela proteção dos bens ambientais com o objetivo de proteger a vida humana e o equilíbrio ambiental. (g.n.)
\end{abstract}

Outra questão que merece uma reflexão é a desigualdade na prestação dos serviços públicos relacionados a distinções sociais. A Declaração dos Direitos do Homem e do Cidadão, proclamada pela Organização das Nações Unidas de 1948, expressa:

Art.1. ${ }^{\circ}$ Os homens nascem e são livres e iguais em direitos. As distinções sociais só podem fundamentar-se na utilidade comum. (g.n.)

A Constituição Federal de 1988 consagra como valor supremo:

Art. $1^{\circ}$ A República Federativa do Brasil, formada pela união indissolúvel dos Estados e Municípios e do Distrito Federal, constitui-se em Estado Democrático de Direito e tem como fundamentos:

(...) omissis

III - a dignidade da pessoa humana;(g.n.)

Na lição de Sarlet (2011, p. 109):

O princípio da dignidade humana é que demanda fórmulas de limitação do poder, prevenindo o arbítrio e a injustiça, na medida em que há de se convir que os direitos fundamentais, ao menos de forma geral, podem ser considerados concretizações das exigências do princípio da dignidade da pessoa humana.

Para Santilli (2005, p. 59): "o meio ambiente ecologicamente equilibrado, essencial à sadia qualidade de vida, é um direito humano fundamental”. Embora não esteja inserido no art. $5^{\circ}$ da Constituição Federal dentre os direitos fundamentais "explícitos”, a doutrina já reconhece o seu caráter fundamental como primado para perpetuação da vida humana.

Rev. de Direito Urbanístico, Cidade E Alteridade | e-ISSN: 2525-989X| Porto Alegre | v. 4 | n. 2 | p. 117-134 | Jul/Dez. 2018 
A desigualdade de acesso aos serviços de saneamento ambiental em função da renda do cidadão em seus domicílios pode ser um fator determinante na distribuição destes serviços, pois se observa nas cidades brasileiras que áreas mais centrais e nobres dispõem destes serviços em detrimento de outras áreas mais afastadas e populares onde não há estes serviços.

A Sociologia investiga essas hipóteses sobre a perspectiva da seletividade hierárquica dos serviços públicos, no sentido de que algumas políticas seriam adotadas para beneficiar prioritariamente e com melhor qualidade de vida as áreas mais ricas em detrimento das áreas mais pobres.

Marques (2000, p. 115) identifica que: "os grupos sociais mais ricos e escolarizados são atendidos por primeiro pelos serviços públicos, posteriormente, beneficiariam os demais cidadãos".

Deste modo, é possível identificar uma seleção hierarquizada dos serviços públicos essenciais, com a diferenciação das áreas atendidas pelos serviços públicos, pois se observa uma relação entre as regiões geográficas das cidades, a renda e a escolaridade da população, em relação aos serviços de infraestrutura das cidades.

Segundo dados disponíveis pelo Ministério da Saúde (2015. p. 1):

São os serviços de infraestrutura, responsáveis diretos pela qualidade de vida da população, pois para cada $\mathrm{R} \$ 1$ investido em saneamento básico, R\$ 4 são economizados na rede de saúde pública na área de doenças causadas por ausência de tratamento de água e esgoto.

Para Moraes (2000, p. 60):

O princípio fundamental consagrado pela Constituição Federal da dignidade da pessoa humana, é um direito individual protetivo, seja em relação ao próprio Estado, seja em relação aos demais indivíduos, estabelecendo um verdadeiro dever fundamental de tratamento igualitário dos próprios semelhantes. (g.n.)

A ausência ou a má distribuição do saneamento ambiental está diretamente relacionada com a qualidade de vida das pessoas, com a interferência nas suas rotinas, com a falta de higiene pessoal, com a exposição a áreas poluídas, na ocorrência frequente de doenças, no baixo rendimento laboral e educacional, na baixa estima e, por conseguinte, no total desprezo às questões ambientais pelo distanciamento das políticas sociais.

Pode-se considerar que residiria neste último fator uma possível explicação à distribuição não uniforme da cobertura dos serviços de saneamento, havendo uma possível relação direta entre a desigualdade de acesso aos serviços públicos e a desigualdade de renda. 
Os aspectos analisados servem para demonstrar a problemática urbana e a má distribuição dos serviços públicos, que são essenciais para que a população tenha qualidade de vida e possa se desenvolver social e economicamente.

\section{CIDADES SUSTENTÁVEIS E A NBR ISO No. 37.120/2017}

As primeiras sociedades urbanas que surgiram foram as comunidades indígenas ou os denominados povos tradicionais ou bárbaros. Com o desenvolvimento das civilizações, esse fenômeno urbano se aprofunda e vamos encontrar na revolução industrial um elemento importante para que a população do campo migre para as zonas urbanas.

Neste sentido, Lefebvre (2015, p. 11) esclarece: "para apresentar e expor a 'problemática urbana', impõe-se um ponto de partida: o processo de industrialização. Sem possibilidade de contestação, esse processo é, há um século e meio, o motor das transformações nas sociedades".

Dessa forma, o surgimento das cidades, com raras exceções, não é realizado de forma planejada. Elas vão surgindo em virtude do comércio, dos serviços públicos que ali vão se aglutinando e atraindo aqueles indivíduos que querem outra opção de vida ou de trabalho, diferente da vida no campo.

Nesta linha de raciocínio Glaeser (2011, p. 52) esclarece que:

As cidades sofrem com as recessões econômicas por causa da perda de empregos e da
redução dos salários, mas os choques negativos também geram consequências indire-
tas, como a agitação social e a queda na receita fiscal, que podem ser igualmente pre-
judiciais.

Assim sendo, duas consequências advém-se desse fenômeno citado por Glaeser: o citadino, com a perda de seu emprego e com a redução do seu poder aquisitivo, busca opções de moradia e alimentação, formando bairros pobres, sem infraestrutura, montados sobre ocupações ilegais e desordenadas; por outro lado, com a perda de arrecadação fiscal, o Poder Público passa a ter uma menor capacidade financeira de investimentos em saneamento básico, educação e lazer, gerando problemas sérios na sustentabilidade urbana.

O problema da insustentabilidade urbana é um fenômeno global no planeta terra, sendo um desafio para todas as nações; pois a falta de planejamento para o surgimento das cidades gera inúmeros problemas sociais, paisagístico e de poluição, quer seja de resíduos sólidos, líquidos e gasosos. 
Desse modo, com a crise ambiental, tem-se buscado esforços para reduzir essa problemática, através de diversas Convenções internacionais, como alternativa na busca de minimizar esse problema, tentando-se construir um paradigma de "cidade sustentável". Segundo Sousa Filho e Carvalho (2015, p. 30) “Cidades sustentáveis são cidades que implementam políticas sustentáveis, que respeitam e preservam o meio ambiente em busca da tão chamada sustentabilidade".

Dessa forma, é importante que as cidades do presente se adequem às regras de sustentabilidade para que, no futuro próximo, tenhamos cidades sustentáveis. Assim sendo, a NBR n ${ }^{\circ}$ 37.120/2017 surge como um caminho para a conquista desta sustentabilidade urbana, motivo pelo qual é extremamente importante detalharmos o surgimento dessa novel Norma Técnica e evidenciar como ela poderá contribuir, beneficiando os moradores desta localidade e de todo o planeta.

A Associação Brasileira de Normas Técnicas-ABNT é o órgão responsável pela normalização técnica no Brasil, fornecendo insumos ao desenvolvimento tecnológico brasileiro. Trata-se de uma entidade privada, sem fins lucrativos e de utilidade pública, fundada em 1940, é membro fundador da Organização Internacional de Normalização, da Comissão Panamericana de Normas Técnicas e da Associação Mercosul de Normalização e a representante oficial no Brasil dessas três instituições e também da Comissão Eletrotécnica Internacional, a normalização técnica dos produtos científicos e tecnológicos documentais é fundamental para a ampla compreensão e identificação dos mesmos.

A ABNT é o órgão nacional de normalização por reconhecimento da sociedade brasileira desde a sua fundação, sendo responsável pela elaboração das Normas Brasileiras (ABNT NBR), elaboradas por seus Comitês Brasileiros (ABNT/CB), Organismos de Normalização Setorial (ABNT/ONS) e Comissões de Estudo Especiais (ABNT/CEE).

Desde 1950 a ABNT atua também na avaliação da conformidade para certificação de produtos, sistemas e rotulagem ambiental. Esta atividade está fundamentada em guias e princípios técnicos internacionalmente aceitos e alicerçada em uma estrutura técnica e de auditores multidisciplinares, garantindo credibilidade, ética e reconhecimento dos serviços prestados.

Trabalhando em sintonia com governos e com a sociedade, a ABNT contribui para a implementação de políticas públicas, promove o desenvolvimento de mercados, a defesa dos consumidores e a segurança de todos os cidadãos. 
As normas da ABNT são utilizadas como padrão para a produção de teses, monografias e dissertações acadêmicas, como o Trabalho de Conclusão de Curso (TCC), que deve ser feito pela maioria dos alunos quando finalizam os cursos de ensino superior no Brasil.

Cada norma brasileira -NBR se destina a uma característica específica da produção acadêmica/científica, por exemplo: NBR 14724: informações para a elaboração de teses, dissertações, trabalhos de conclusão de curso (elementos pré-textuais, textuais e pós-textuais), NBR 6022: informações para artigos em publicação periódica científica impressa, NBR 15287: informação e documentação à respeito de Projeto de pesquisa, NBR 6023: critérios e ordem em relação às referencias (a respeito da transcrição e informações a serem retiradas de documentos ou de outras fontes de informação), NBR 10520: informações sobre as citações em documentos, NBR 6028: informações sobre os requisitos para apresentação de resumos e redações, dentre outras.

Ademais, a NBR é utilizada para a produção de produtos e serviços que devam ser padronizados com a finalidade de terem qualidade e confiabilidade. Cada norma técnica aprovada e publicada pela ABNT possui um código específico, normalmente iniciado pela sigla NBR.

\section{ORGANIZAÇÃO INTERNACIONAL PARA PADRONIZAÇÃO}

A ISO é a sigla de Internacional Organization for Standardization, ou "Organização Internacional para Padronização”, em português. A ISO foi criada em Genebra, na Suiça, em 1947.

A sigla para International Organization for Standardization deveria ser IOS e não ISO, no entanto, como em cada país de línguas diferentes existiria uma sigla diferente, os fundadores decidiram escolher uma só sigla para todos os países: ISO. Esta foi a sigla escolhida porque em grego isos significa "igual", o que se enquadra com o propósito da organização em questão.

Segundo Freitas (2011, p. 27): “a ISO tem como objetivo principal aprovar normas internacionais em todos os campos técnicos, como normas técnicas, classificações de países, normas de procedimentos e processos, e etc". No Brasil, a ISO é representada pela ABNT (Associação Brasileira de Normas Técnicas).

A ISO promove a normatização de empresas e produtos, para manter a qualidade permanente. Suas normas mais conhecidas são a ISO 9000, ISO 9001, ISO 14000 e ISO 14064. 
As ISO 9000 e 9001 são um sistema de gestão de qualidade aplicado em empresas, e ISO 14000 e ISO 14064 são um sistema de gestão ambiental.

A ISO 9000 E 9001 são um conjunto de ações preventivas, para garantir e padronizar um serviço ou um produto. Para uma empresa receber qualquer certificado da ISO, ela deve passar por um projeto com diversas fases de comprovação de processos sistematizados e de qualidade para garantir que a implementação dos processos seja feita de modo correto.

Segundo a Proteste (2018, p. p) "nas questões ambientais, nenhum órgão público ou empresa pode se auto certificar. Há a necessidade de uma entidade certificadora com expertise na gestão ambiental, para que esta promova os estudos necessários a certificação".

Por esse motivo, em 1993, a ISO reuniu diversos profissionais e criou um comitê intitulado Comitê Técnico TC 207 que teve como objetivo desenvolver Normas, série 14000, nas áreas relacionadas ao meio ambiente.

Ainda segundo a Portestes (2018, p. 1):

\begin{abstract}
O comitê foi dividido em vários subcomitês: Subcomitê 1: Desenvolveu uma norma relativa aos sistemas de gestão ambiental, Subcomitê 2: Desenvolveu normas relativas às auditorias na área de meio ambiente, Subcomitê 3: Desenvolveu normas relativas à rotulagem ambiental, Subcomitê 4: Desenvolveu normas relativas ao desempenho (performance) ambiental, Subcomitê 5: Desenvolveu normas relativas à análise durante a existência (análise de ciclo de vida), Subcomitê 6: Desenvolveu normas relativas a definições e conceitos, Subcomitê 7: Desenvolveu normas relativas à integração de aspectos ambientais no projeto e desenvolvimento de produtos, Subcomitê 8: Desenvolveu normas relativas à comunicação ambiental e o Subcomitê 9: Desenvolveu normas relativas às mudanças climáticas. (g.n.)
\end{abstract}

Desse modo, se percebe a importância da certificação nas áreas relacionadas ao meio ambiente.

\title{
4 O DESENVOLVIMENTO SUSTENTÁVEL DE COMUNIDADES.
}

A primeira norma técnica para cidades sustentáveis do Brasil foi aprovada pela Associação Brasileira de Normas Técnicas (ABNT), recebendo o nome de NBR ISO 37.120/2017. Esta norma define e estabelece metodologias para um conjunto de indicadores relacionados ao desenvolvimento sustentável de comunidades urbanas, com o objetivo de orientar e medir o desempenho de serviços urbanos e qualidade de vida nas cidades.

O estudo e tradução desta norma internacional foi realizado pela Comissão de Estudos Especial (CEE) n ${ }^{\circ} .268$ da ABNT, uma comissão semelhante a da Technical Committee TC $n^{\circ}$. 
268 da ISO, a Sustainable cities and communities, que atuou na confecção da norma internacional.

A CEE $n^{\circ} .268$ foi coordenada pelo professor Alex Kenya Abiko do Departamento de Engenharia de Construção Civil (PCC) da Escola Politécnica (Poli) da USP. Segundo Abiko (2017, p. 1):

Trata-se de uma tradução e adaptação para a língua portuguesa da norma ISO 37120:2014 - Sustainable development of communities - Indicators for city services and quality of life. "Esses indicadores podem ser utilizados para rastrear e monitorar o progresso do desempenho da cidade no que se refere à sustentabilidade.

A iniciativa de ter uma norma nacional sobre o assunto nasceu das atividades de pesquisa do próprio Departamento de Engenharia de Construção Civil da Poli, que tem uma linha de estudos em planejamento e engenharia urbanos, o que possibilitou contar com a colaboração de diversos pesquisadores deste departamento.

A NBR ISO 37.120/2017 contém 100 indicadores de sustentabilidade urbana e trata dos aspectos ambiental, econômico, social e tecnológico. Entre outros, esse documento tem por objetivo ajudar os governos Municipal, Estadual e Federal a medir a sustentabilidade das cidades sem estabelecer padrões rígidos.

Entretanto, a norma não fala se uma cidade é sustentável ou não, mas estabelece quais requisitos devem ser avaliados para se medir essa sustentabilidade. Engloba indicadores de diferentes áreas, tais como: economia, educação, energia, ambiente, finanças, serviços de emergência, saúde, lazer, segurança, resíduos, transportes, telecomunicações, água, planejamento urbano etc.

Além do setor público, a NBR nº $37.120 / 2017$ pode ser usada pelas empresas para que atestem para clientes e governo o quão sustentável são seus empreendimentos e, dessa forma, potencializar o seu compromisso com a responsabilidade ambiental, colhendo frutos empresariais.

A norma nasceu de uma necessidade acadêmica, com o intuito de medir a sustentabilidade das cidades por meio da investigação de indicadores sociais, ambientais e econômicos, o que no Brasil não era feito. Entretanto, se sabe que mais de 150 sistemas de medição foram desenvolvidos e adotados em diversos países, como Estados Unidos, Austrália, França, Inglaterra, África do Sul, ente outros, sendo eles realizados por estes países. 
Importante destacar que o melhor sistema para se apurar e evidenciar esses indicadores é a norma da ISO, porque é resultado da discussão e trabalho de uma entidade que reúne quase todos os países do mundo, o que dá maior credibilidade e torna a norma internacional.

Assim, percebe-se que as normas de outras entidades trazem elementos que são indicadores das realidades locais, o que torna mais difícil implementá-las por serem de contextos sociais e econômicos diferentes, enquanto a ISO sempre busca unir o melhor de todas as normas em uma só.

Selecionada a norma ISO, a Comissão a Comissão nº. 268268 passou a trabalhar na tradução do documento, pois não bastava apenas traduzir para a língua portuguesa, tinha que se fazer uma avaliação técnico-científica, adotando o documento para a realidade brasileira. Ademais, não se pode alterar uma norma ISO para adotá-la livremente como uma norma NBR, é preciso fazer adequações em vários itens para que a norma faça sentido à realidade brasileira, o que normalmente é feito por meio de notas.

Como exemplo de nota brasileira, podemos citar a definição do termo "favela", que também pode ter como sinônimos no Brasil dois termos: assentamentos precários ou assentamentos subnormais, como utilizado pelo Instituto Brasileiro de Geografia e Estatística (IBGE).

Esse trabalho envolveu diversas instituições e órgãos públicos, tais como: a Caixa Econômica Federal, o Ministério das Cidades, a Companhia de Saneamento Básico do Estado de São Paulo(Sabesp), o Conselho de Arquitetura e Urbanismo (CAU), a Câmara Brasileira da Indústria da Construção (CBIC), o Sindicato da Habitação (Secovi), o Conselho Brasileiro da Construção Sustentável (CBCS), a Poli, Faculdade de Arquitetura e Urbanismo (FAU) da Universidade de São Paulo (USP), a Companhia de Desenvolvimento Habitacional e Urbano do Estado de São Paulo (CDHU), o Instituto de Engenharia, entre outras, que compuseram a CEE $\mathrm{n}^{\circ} .268$.

As próximas normas a serem desenvolvidas em conformidade com a CEE $n^{\circ} .268$ são as de Sistemas de Gestão para o Desenvolvimento Sustentável, cujos trabalhos já estão avançados como as de Cidades Inteligentes e as de Cidades Resilientes, em nível mais preliminar.

Segundo a FGV Projetos (2018, p. p):

As Cidades inteligentes (CI) são projetos nos quais um determinado espaço urbano é palco de experiências de uso intensivo de tecnologias de comunicação e informação sensíveis ao contexto (IoT), de gestão urbana e ação social dirigidos por dados (Data-Driven Urbanism). Esses projetos agregam, portanto, três áreas principais: Internet das Coisas (objetos com capacidades infocomunicacionais avançadas), Big Data (processamento e análise de grandes quantidades de informação) e 
Governança Algorítmica (gestão e planejamento com base em ações construídas por algoritmos aplicados à vida urbana).( g.n.)

O objetivo maior é criar condições de sustentabilidade, melhoria das condições de existência das populações e fomentar a criação de uma economia criativa pela gestão baseada em análise de dados.

Segundo o Ministério da Integração Nacional (2018, p. p):

Uma cidade resiliente é aquela que tem a capacidade de resistir, absorver e se recuperar de forma eficiente dos efeitos de um desastre e de maneira organizada prevenir que vidas e bens sejam perdidos, a cargo do Escritório das Nações Unidas para a Redução do Risco de Desastres - UNISDR/ONU. (g.n.)

Um dos pontos fundamentais são os indicadores da NBR n ${ }^{\circ} .37 .120 / 2017$, que não são ordenados de forma hierárquica, sendo classificados em temas de acordo com os diferentes setores e serviços prestados em uma cidade, englobando indicadores de diferentes áreas, tais como: economia, educação, energia, ambiente, finanças, serviços de emergência, saúde, lazer, segurança, resíduos, transportes, telecomunicações, água, planejamento urbano etc.

Segundo Abiko (2017):

Os indicadores são divididos em: Requisito 05 - Econômicos; Requisito 06 - Educação; Requisito 07 - Energia; Requisito 08 - Meio Ambiente; Requisito 09 - Finanças; Requisito 10 - Resposta a incêndios e emergência; Requisito 11 - Governança; Requisito 12 - Saúde; Requisito 13 - Recreação; Requisito 14 - Segurança; Requisito 15 - Habitação; Requisito 16 - Resíduos sólidos; Requisito 17 - Telecomunicações e inovações; Requisito 18 - Transporte; Requisito 19 - Planejamento Urbano; Requisito 20 - Esgotos; Requisito 21 - Água e Saneamento. (g.n.)

A interpretação dos indicadores deve ser feita revendo os resultados de vários outros indicadores transversais, a fim de que não haja conclusões distorcidas ou incompletas. Além disso, deve-se considerar o contexto no momento da análise dos resultados.

Os resultados dos indicadores da NBR $n^{\circ}$. 37.120/2017 podem ser usados como ferramentas para a tomada de decisões governamentais, diante das informações que permitam orientar as políticas de planeamento e gestão, de outro modo a certificação de cidades sustentáveis tem a tendência de ser um diferencial entre as cidades do mundo moderno, uma espécie de competição positiva, pois atrairão negócios para seus sítios e qualidade de vida para a população.

Esta certificação das cidades passará a ser, praticamente, uma fonte de fomento de negócios e uma ferramenta obrigatória para atração de novos investimentos, tanto no setor pú- 
blico como no setor privado, pois esses indicadores podem ser utilizados para rastrear e monitorar o progresso e o desempenho dos diferentes índices das cidades, uma vez que para atingir o desenvolvimento sustentável, todo o sistema urbano necessita ser levado em consideração.

\section{CONCLUSÃO}

A problemática que envolveu essa pesquisa girou em torno da NBR no . 37.120/2017, a primeira norma brasileira sobre o Desenvolvimento Sustentável de comunidades e indicadores para serviços urbanos e qualidade de vida. Esta novel norma define e estabelece metodologias para um conjunto de indicadores com a finalidade de orientar e medir o desempenho de serviços urbanos e a qualidade de vida da população.

A pesquisa atingiu seus objetivos ao analisar a NBR $n^{0} .37 .120 / 2017$, pois ela se destina a qualquer cidade ou entidade governamental local que se comprometa a medir o seu desempenho de forma comparável, independentemente do seu tamanho, localização ou nível de desenvolvimento econômico. Estas informações englobam indicadores de diferentes áreas, como por exemplo: economia, educação, energia, meio ambiente, finanças, serviços de emergência, saúde, lazer, segurança, resíduos sólidos, transportes, telecomunicações, água, planejamento urbano, etc. Os resultados destes indicadores podem ser usados como ferramentas para a tomada de decisões que permitam nortear as políticas de planeamento e gestão.

Dessa forma, conclui-se que os indicadores medidos pela NBR $\mathrm{n}^{\circ} .37 .120 / 2017 \mathrm{em}$ relação aos serviços urbanos e qualidade de vida, podem ser usados como ferramentas cruciais pelos gestores municipais, políticos, pesquisadores, professores, líderes empresariais, planejadores, arquitetos, urbanistas, designers e outros profissionais, pois ajudam a garantir que sejam colocadas em prática, políticas que promovam a habitabilidade, educação, saúde, saneamento básico, água encanada, destinação de resíduos, sustentabilidade e economia urbana, tornando as cidades economicamente atrativas e prósperas globalmente, pois as cidades precisam de indicadores para medir seu desempenho, melhorar a qualidade de vida da população e promover a sustentabilidade ambiental. 


\section{REFERÊNCIAS}

ABNT. ASSOCIAÇÃO BRASILEIRA DE NORMAS TÉCNICAS. NBR ISO 37120:2017 ISO 37120:2014: Desenvolvimento sustentável de comunidades - Indicadores para serviZços urbanos e qualidade de vida. Disponível em: <http://www.abntcatalogo.com.br/norma.aspx?ID=366389>. Acesso em: 29 jul. 2018.

ABIKO, Alex Kenya. Brasil recebe norma técnica NBR ISO 37120 para cidades sustentáveis. 2017. Disponível em: < https://www.aecweb.com.br/cont/m/rev/brasil-recebe-norma-tecnica-nbr-iso-37120-para-cidades-sustentaveis_15947_10_0>. Acesso em: 01 ago. 2018.

ASSIS, Fátima Rangel dos Santos de. Produzir, Consumir e Preservar: responsabilidades empresarial, administrativa e jurídica. São Paulo: Forense, 2016.

BARBIERI, José Carlos. Desenvolvimento Sustentável. São Paulo: Vozes, 2015.

BRASIL. Constituição (1988). Constituição da República Federativa do Brasil. Brasília, DF: Senado Federal, 1988.

Instrução Normativa CTNBio $\mathbf{n}^{0}$ 20/2001. Disponível em: <http://www.ctnbio.gov.br>. Acesso em: 02 ago. 2018.

Lei no 6.938/81 - PNMA - Política Nacional do Meio Ambiente. Disponível em: <http://www.planalto.gov.br/ccivil_03/Leis/L6938.htm>. Acesso em: 02 ago. 2018.

Lei 10.406/02. Código Civil. Disponível em: < http://www.planalto.gov.br/ccivil_03/leis/2002/110406.htm>. Acesso em: 02 ago. 2018.

COPOLA, Gina. Elementos de Direito Ambiental. 1. ed. Rio de Janeiro: Editora Temas \& Ideias, 2003.

DI SARNO, Daniela Campos Libório. Elementos de Direito Urbanístico. São Paulo: Manole, 2004.

FERRAJOLI. Luigi. Por uma Teoria dos Direitos e dos bens fundamentais. Tradução Alexandre Salim et.al. Porto Alegre: Livraria do Advogado, 2006.

FGV PROJETOS. Cidades inteligentes. Disponível em: <https://fgvprojetos.fgv.br/noticias/oque-e-uma-cidade-inteligente>. Acesso em: 29 jul. 2018.

FIORILLO, Celso Antônio Pacheco. Curso de direito ambiental brasileiro. São Paulo: Saraiva, 2016.

, Celso Antônio Pacheco. Estatuto da Cidade comentado. São Paulo: Revista dos Tribunais, 2005.

FREITAS, Melyna Resende de. A norma ISO 9000 e o modelo de excelência em gestão garantindo a qualidade na prestação de serviços em uma empresa junior de consultoria. 2011. Disponível em: <http://www.ufjf.br/ep/files/2014/07/2011_1_Melyna.pdf>. Acesso em: 01 jul. 2018.

FREITAS, Vladimir Passos de. A Constituição Federal e a efetividade das normas ambientais. 3. ed. São Paulo: Revista dos Tribunais, 2005.

GLAESER, Edward L. Os Centros Urbanos: a maior invenção da Humanidade. Rio de 
janeiro: Campus Editor, 2011.

IBGE. Instituto Brasileiro de Geografia e Estatística. Disponível em: <https://www.ibge.gov.br>. Acesso em: 29 jul. 2018.

INFRAERO. Empresa Brasileira de Infraestrutura Aeroportuária. Disponível em: <www4.infraero.gov.br/aeroportos/aeroporto-internacional-de-manaus-eduardo-gomes>.

Acesso em: 29 jul. 2018.

ISO. International Organization for Standardization, Organização Internacional para Padronização e Normalização. Disponível em: 〈https://www.site iso.org>. Acesso em: 29 jul. 2018.

LEFEBVRE, Henri. Direito à Cidade. São Paulo: Centauro Editora: 2015.

MACHADO, Paulo Afonso Leme. Direito Ambiental Brasileiro. São Paulo: Malheiros, 2013.

MEIRELLES, Hely Lopes. Direito Administrativo Brasileiro. 30. ed. São Paulo: Malheiros, 2005 .

MELLO, Celso Antonio Bandeira de. Curso de Direito Administrativo. São Paulo: Malheiros, 2002.

MINISTÉRIO DA INTEGRAÇÃO NACIONAL. Cidades resilientes. Disponível em: <http://www.mi.gov.br/cidades-resilientes >. Acesso em: 29 jul. 2018.

MINISTÉRIO DA SAÚDE. Saneamento básico. Disponível em: <http://www.portalsaude.saude.gov.br/saneamento_basico.htmf >. Acesso em: 29 jul. 2018.

ONU. Organização das Nações Unidas. Declaração universal dos direitos humanos. Aprovada pela Resolução n. 217-A (III) da Assembleia Geral das Nações Unidas, realizada em 10 de dezembro de 1948. Disponível em: 〈http://www.onu.org.br/img/2014/09/DUDH.pdf>. Acesso em: 29 jul. 2018.

Declaração do Rio sobre Meio Ambiente e Desenvolvimento. Disponível em: <http://www.mma.gov.br/port/sdi/ea/documentos/convs/decl_rio92.pdf >. Acesso em: 16 jul. 2018.

PINTO, Victor Carvalho. Direito Urbanístico, Plano Diretor e Direito de Propriedade. São Paulo: Revista dos Tribunais, 2014.

PORTAL BRASIL. Medicina e saúde, cólera. Disponível em: <http://www.portalbrasil.net/medicina_colera.htmf >. Acesso em: 29 jul. 2018.

PROTESTE, Associação Brasileira de Defesa do Consumidor. Disponível em: <http://www.proteste.org.br/quem-somos>. Acesso em: 29 de jul. 2018.

SARLET, Ingo Wolfgang; FENSTERSEIFER, Tiago. Direito Constitucional Ambiental: Estudos sobre a Constituição, os Direitos Fundamentais e a Proteção do Ambiente. São Paulo: Revista dos Tribunais, 2011.

SANTILLI, Juliana. Socioambientalismo e novos direitos: proteção jurídica à diversidade biológica e cultural. São Paulo: Fundação Peirópolis, 2005.

SILVA, José Afonso da. Direito ambiental constitucional. 5. ed. São Paulo: Malheiros, 2004.

Rev. de Direito Urbanístico, Cidade E Alteridade | e-ISSN: 2525-989X| Porto Alegre | v. 4 | n. 2 | p. 117-134 | Jul/Dez. 2018 
Direito urbanístico Brasileiro. São Paulo: Malheiros, 2012.

SILVA. Jussara Maria Pordeus e. Ordenação das Cidades e o Papel do Direito Urbanístico: O licenciamento Urbanístico no Município de Manaus. Manaus: Editora da Amazônia, 2014.

SOUSA FILHO, Antenor pereira de.; CARVALHO, Mariana Aparecida Adalberto de. Os Reflexos da Logística Reversa Presentes numa cidade Sustentável. In Cidade do Futuro em Poluição. Rio de janeiro: Lumen juris, 2015. 